\title{
AN EXAMINATION OF THE GROWING LEVEL OF INCOME INEQUALITY
}

\author{
Allen L. Webster \\ Department of Finance and Quantitative Methods, \\ Foster College of Business, Bradley University, Peoria, Il 61625, USA
}

Received 2014-03-03; Revised 2014-03-26; Accepted 2014-04-02

\begin{abstract}
This study examines the dispute surrounding the perceived gap in incomes of different socio-economic classes. The trend in income inequality based on the Gini coefficient in America in contrast to that of other nations in the Organization for Economic Cooperation and Development is displayed. Global and national forces seen as causes for the increased separation of income levels are discussed. Continued economic disparity can threaten public welfare and create social unrest that will ultimately prove detrimental to the social and economic fabric that bind a nation. This issue will continue to remain at the forefront of our public policy and will play a significant role in the future course of our economic policy.
\end{abstract}

Keywords: Socio-Economic, Income Inequality, Public Welfare, Economic Disparity

\section{INTRODUCTION}

Over the past few of years the problem of income inequality has received intensified scrutiny. Growing concern has arisen as seemingly countless of reports and formal studies have revealed a growing gap between the rich and the less fortunate. According to the U.S. Census Bureau this disparity has been increasing for decades (CBO, 2011). Average real after-tax income of the top $1 \%$ of wage earners has increased $275 \%$ since 1979 . The income of the remaining top quartile (81 to 99th percentile) increased by only $65 \%$. The vast majority of Americans in the middle class (21 to 80th percentile) enjoyed only a $37 \%$ increase in income since 1979 . The bottom quintile reported the least growth at $18 \%$. This trend clearly has the effect of creating wider gaps among the economic classes.

Much the same results are found if the distribution of income is viewed in terms of shares of national income received by various cohorts within the economy. Based on pre-tax and pre-transfer market income, excluding nontaxable fringe benefits such as health insurance but including realized capital gains, the share of total annual income received by the top $1 \%$ has more than doubled from 9\% in 1976 to $20 \%$ in 2011 (Piketty and Saez,
2003). From 1968 to 2010, the share of national income earned by the top $20 \%$ rose from 42.6 to $50.2 \%$. Even these gains were concentrated at the very top. Furthermore, the share to those income earners making up the middle $60 \%$ within the income stratum actually declined from 53.2 to $46.5 \%$. Those on the lower rungs of the income ladder suffered an even greater decrease in their share of national income. Their share fell by $18 \%$.

\section{COMPARING THE U.S. TO OTHER NATIONS}

Apparently, the United States does not measure well against other nations. Income inequality in the U.S. is substantially higher than in many other developed nations. The Organization for Economic Cooperation and Development (OECD), of which the United States is a member, reported that the U.S. has one of the highest levels of income inequality and relative poverty of the 34 nations that make up the organization. The U.S. is followed only by Chile, Mexico and Turkey in terms of these rather disparaging measures (Luhby, 2014).

There are many methods by which income inequality is measured. One of the most common is the Gini coefficient (or ratio). This measure was developed by the Italian statistician and sociologist, Corrado Gini and 
published in his 1912 paper "Variability and Mutability" (Gini, 1912). Based on the Lorenz curve, the Gini coefficient offers a measure of the discrepancy between the absolute equality of income distribution and the actual distribution prevailing within any geographical area. The Gini coefficient registers between zero and one. A coefficient of zero indicates perfect income equality, while a coefficient of unity indicates perfect inequality. The higher the coefficient is the greater the degree of inequality.

Figure 1 shown here provides the Gini coefficient for selected OECD countries (WB, 2014). Russia, which is not a member nation is also included for comparison. The upper values represent the coefficients before taxes and transfers while the lower values are the ratios after taxes and transfers have reduced the degree of inequality. As noted above, it can be seen that only Chile, Turkey and Mexico report pre-tax Ginis greater than the U.S. The after tax Gini for Russia is unavailable. The OECD averages of 0.316 and 0.463 are also included.

It is interesting to note the net changes in the degree of inequality after taxes and transfers. The bars in Fig. 2 represent the decreases in the Gini ratios for each of the nations once taxes and transfers are taken into account. For example, Canada's Gini coefficient was reduced by over 0.10 through public efforts to combat income inequality.

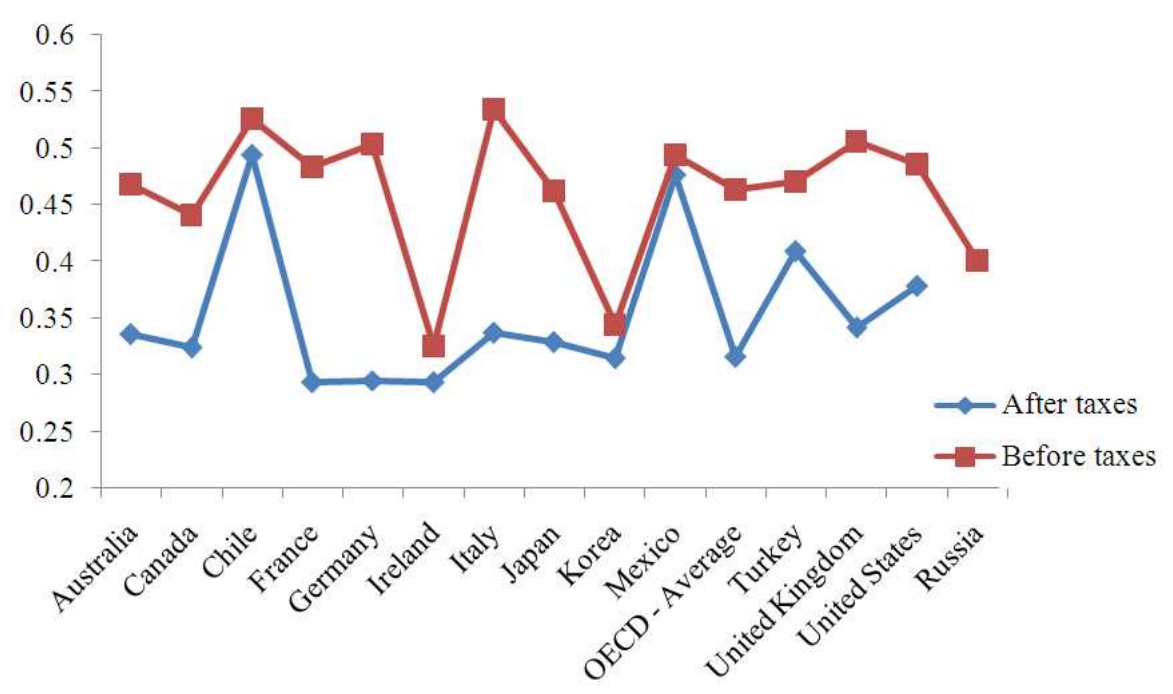

Fig. 1. Gini coefficients for OECD nations-2011

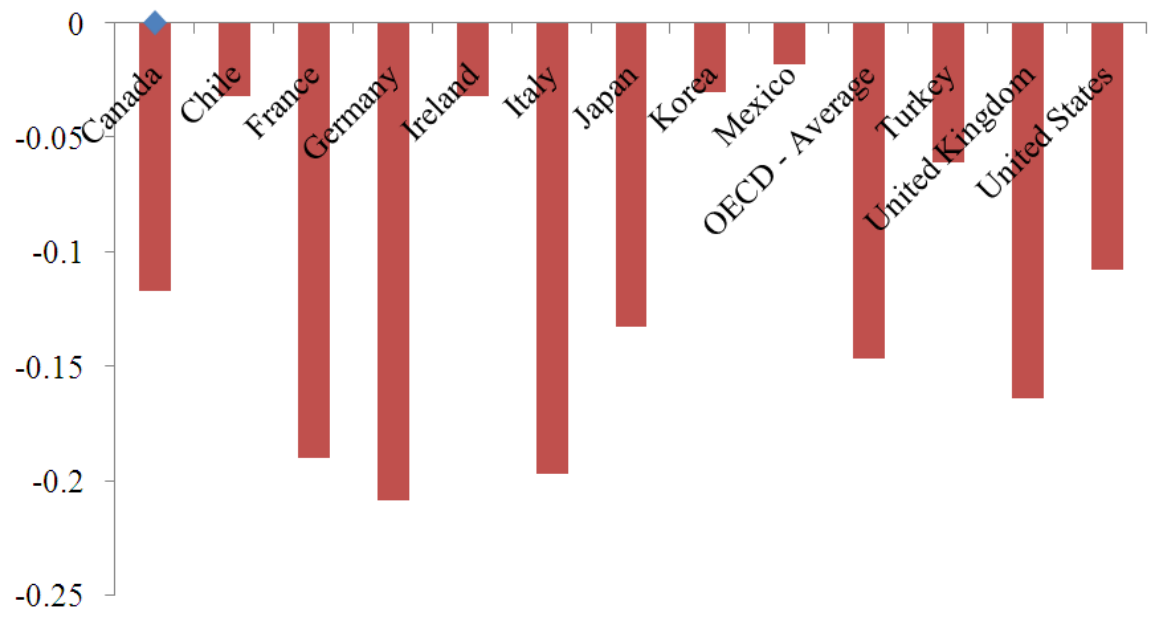

Fig. 2. Reductions in the Gini coefficients due to taxes and transfers 
Clearly, France, Germany and Italy reduced their coefficients the most while Chile, Ireland, Korea and Mexico had very little effect on the coefficients as a result of transfers from the wealth to the poor. The mean reduction was 0.1106 and the median was 0.117 . The less well of in Germany benefited the most as that nation's Gini coefficient dropped by 0.209 but that of Mexico fell the least by 0.018 . The U.S. reduction was 0.108 . The mean OECD decrease was 0.147.

From these figures, it becomes rather undeniable that income inequality is a grave concern across the globe. According to a report from Oxfam, a worldwide development organization that mobilizes the power of people against poverty, the combined wealth of the 85 richest people in the world is equal to that of 3.5 billion people-or half the global population (Oxfam, 2014). Among the report's other findings, it notes that $70 \%$ of the world's population reside in countries where income inequality has risen since the 1980 s and $1 \%$ of families in the world own nearly half, $46 \%$, of the world's wealth, or $\$ 110$ trillion.

\section{TRENDS IN THE US}

This rather unfavorable comparison with other nations forces the question as to why the U.S. has been unable or unwilling to take more concerted effort to reduce the extent of income inequality in our economy. Lindert and Williamson (2011) argue that inequality is worse today than it was in 1774 . Wealth, they contend, was more evenly distributed throughout the 13 colonies than it is today among the 50 states. Their estimate of the Gini coefficient among the 13 colonies was 0.437 which indicates greater equality than the 2012 before-tax coefficient of 0.486 found in the U.S. today.

As seen in Fig. 3, the Gini coefficient indicates a strong upward trend in income inequality over time.

The trend doesn't show any improvement when the data are examined from the standpoint of age distribution. As seen in Fig. 4, the U.S. Census Bureau reported that Americans in their prime earning years ranging from 35 to 44 suffered the greatest increase in the income gap since the early 1990s.

It would seem that the recent Great Recession, dating roughly from mid-2007 to December 2012, has exacerbated the problem. Workers in the lower income brackets were the among the first to lose their jobs as the recession told control of the economy. The unemployment rate for less skilled workers rose more than that suffered by those in the skilled trades and workers who had gained higher levels of education.

Further, the recovery over the past two years has not been an even one. In 2011 the U.S. Gini stood at 0.475, a $1.3 \%$ rise over the previous year and the first significant annual increase since 1993. Today it stands at 0.486 . It has not been an equal-opportunity recovery.

On a brighter side, a more in-depth perspective reveals that everyone is getting richer. The Congressional Budget Office recently completed a study of average household income beginning in 1979 (2010).

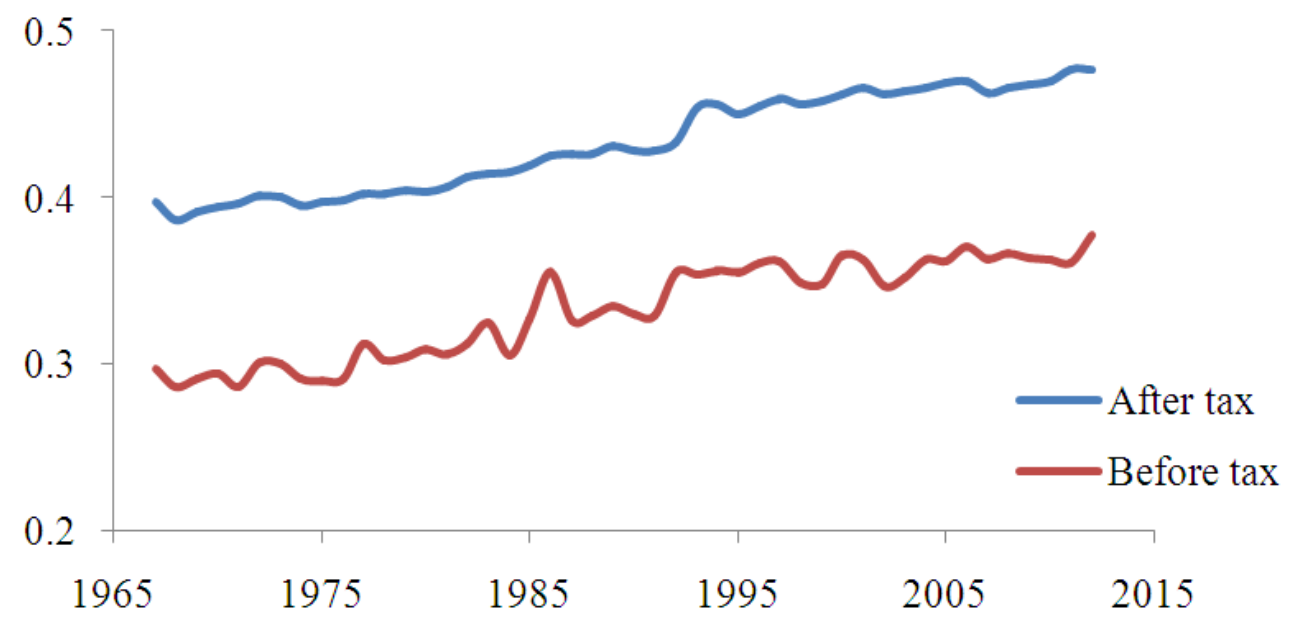

Fig. 3. Gini Coefficients in the U.S. over time 


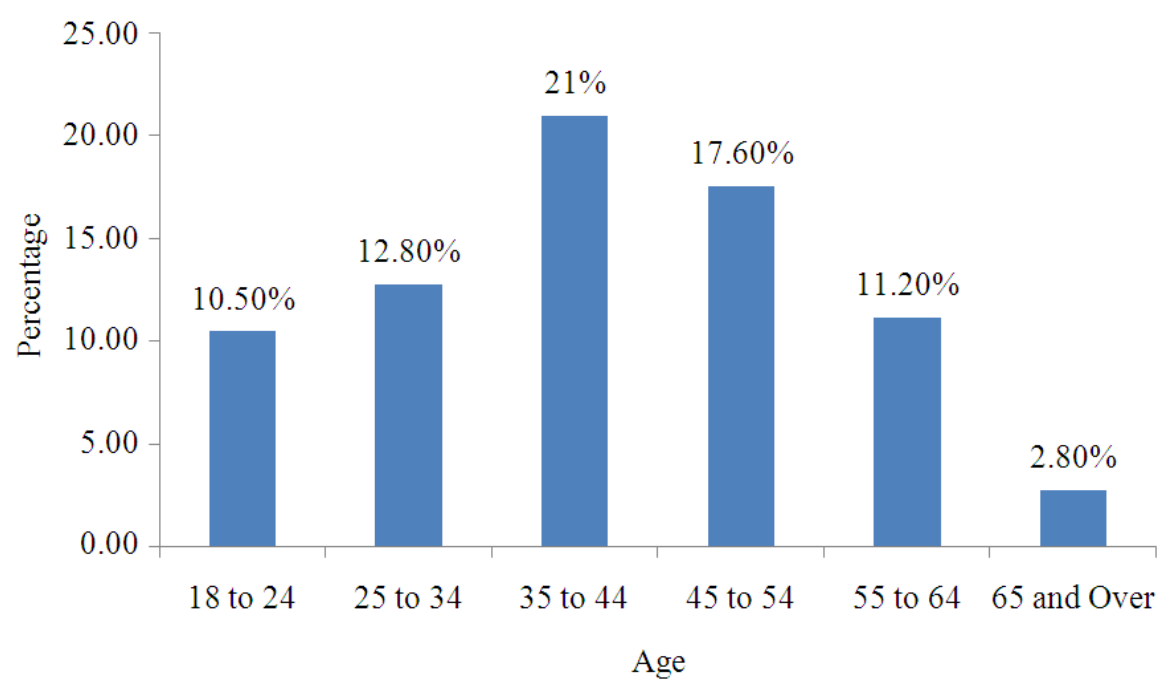

Fig. 4. Changes in the income gap among age groups

The study separated households into quintiles and looked at inflation-adjusted, after-tax incomes of significance, it was found that incomes rose for all groups over the period. Those in the lowest $20 \%$ of households enjoyed an $18 \%$ rise in income since 1979 . Americans ranging from the 21 st to the 80 th percentile reported a $60 \%$ jump while a $65 \%$ increase was evidenced for those in the 81 st through 99th percentiles. Americans across the spectrum have benefited from higher incomes.

These numbers in and of themselves may indicate worsening problem in terms of income inequality. If those at the upper end of the income spectrum are receiving larger increases in their income, as shown in the figures just cited, it can only be concluded that the income gap is widening. The issue becomes more acute when, as noted above, the statement that the upper $1 \%$ of income-earners experienced a $275 \%$ increase in recent years is factored in.

Nevertheless, lower incomes and the poverty-level conditions they often precipitate are very fluid and transitional in nature. The U.S. Census Bureau examined the dynamics of poverty during the 2004-2006 period. The study showed that in many instances households moved in and out of poverty conditions in a transitory fashion. During that time period, $29 \%$ of people experienced a period of poverty lasting at least two months. But even those poverty intervals were typically of a rather short duration, with almost half ending within four months of those in poverty in 2004, almost $42 \%$ were not in poverty in 2006.

\section{IDENTIFYING CAUSES FOR INEQUALITY}

Much of the recent attention devoted to the income gap centers on identifying causes for its persistence. One of the most commonly referenced sources of inequality is seen as an advancing technology and the requirement it places on higher education levels. After a somewhat prolonged period of decline, the college wage-premium has grown dramatically in the past few years. This has driven a deeper wage between better educated workers and those with lesser skills. This educational divide accelerates even further the disparities among workers in that the wage gap also widens between those who hold only bachelor's degrees and those with graduate degrees.

Becker and Murphy (2007) point out that in 1980, an American with a college degree earned about $30 \%$ more than an American who stopped education at high school. But, in recent years, a person with a college education earned roughly $70 \%$ more. Meanwhile, the premium for having a graduate degree increased from roughly $50 \%$ in 1980 to well over $100 \%$ today. The labor market is placing a greater emphasis on education, dispensing rapidly rising rewards to those who stay in school the longest. Becker and Murphy (2007) continue by noting that the earnings gap is widening because the demand for the educated and those with skills is growing.

This is hardly surprising, given technological developments required in the work place and a general 
shift in economic activity to more education-intensive activities. The result is a boost in the demand for bettereducated workers, while depressing the job opportunities and wages of the less skilled.

College degrees across our campuses also garner pronounced differences in income levels. Graduates in the hard sciences, engineering and the business fields enjoy substantially higher salaries than do those with degrees in the arts, humanities and many of the social sciences. Given the rather high cost of education these days, this fact clearly warns students to carefully choose their educational track early in their career.

Globalization has also been cited as a cause of inequality. This may be particularly true in the United States were so many skilled and higher-paying jobs are outsourced overseas. Globalization is defined as the free movements of goods, services and capital across borders. Given cheap labor, cheap land and a host of available resources abroad, many jobs that once went to American workers are now being sent offshore.

Blinder (2007), professor of economics at Princeton University and a noted "free trader," argues that open boarders are a desirable practice. But he admits that the outcome can be painful for the 30 to 40 million American workers whose jobs are "offshoreable." This condition will continue due to two inexorable forces. The first is technology, especially information and communications technology, which has been improving at an astonishing pace in recent decades. This actually alters our entire perception of what constitutes international trade. The world used to think that international trade meant shipping items in boxes across borders.

However, in a more modern sense, a growing list of essential services can be zapped across international borders electronically. It has become common practice for many companies to establish call centers in foreign locations. This activity of electronic service delivery has already extended to computer programming, a variety of engineering services, accounting, security analysis and many other areas that threaten job-losses in the American economy. It's electrons that move, not boxes. Blinder points out that trade restriction cannot hamper the transmission of electrons.

A pronounced decline in the rate of unionization within the US economy also contributes to the growing wage gap. According to the BLS (2014), the union membership rate stands at $11.3 \%$ or 14.5 million workers. In 1983, the figures were $20.1 \%$ or 17.7 million members. The impact of such dynamics on the wage gap can be clearly seen when it is considered that in 2013 the median weekly earnings for union members was \$950, while those who were not union members had median weekly earnings of only $\$ 750$. As union membership wanes and those who do not enjoy the elevated salaries paid to upper management are minimalized, the gap must widen.

On the contrary, Galbraith (2012), an economics professor at the University of Texas in Austin, holds that many of the arguments cited above offer little explanation for the growing wage gap. He points out that the disparity has been prominent in many other nations across the globe that have not experienced these phenomenons. He concludes that economic inequality has been rising in much the same manner around the world since 1980 . This rise appears to be the result of changes the world's financial forces have thrust on the global economy. Galbraith insists that the causes of inequality are a macroeconomic issues founded on the power and its use in the financial center-both within nations and across the globe. The discussion of inequality, he maintains, tends to be improperly viewed by current analysts in a myopic manner as a microeconomic issue in which marketplace perspectives that stresses individual-level characteristics, like the demand for skills, hold center stage. Instead, Galbraith insists, a much wider perspective must be taken that views the matter on a much grander scale encompassing entire nations and even the entire planet as the stage on which this all plays out. The Great recession did not only afflict workers at the lower wage scale. Many higher-paying jobs were also lost during the Great Recession. As the unemployment rate rose during 2007 and 2008 to its height in October of 2009 at $10 \%$, many American workers found themselves facing replacement by cheaper foreign labor or just simply dismissed from the work force. This is evident from Fig. 5. As the recession receded and was officially declared at an end in December 2012, the unemployment rate fell to its current level of $6.6 \%$ (preliminary March 2014).

However, those workers who did find gainful employment had to settle for lower paying semi-skilled or unskilled jobs. The better paying jobs held prior to the Recession were replaced by those with less pay and lower benefits. Obviously, this added to the growing wage gap we are currently witnessing. 
Allen L. Webster / American Journal of Economics and Business Administration 6 (1): 11-18, 2014

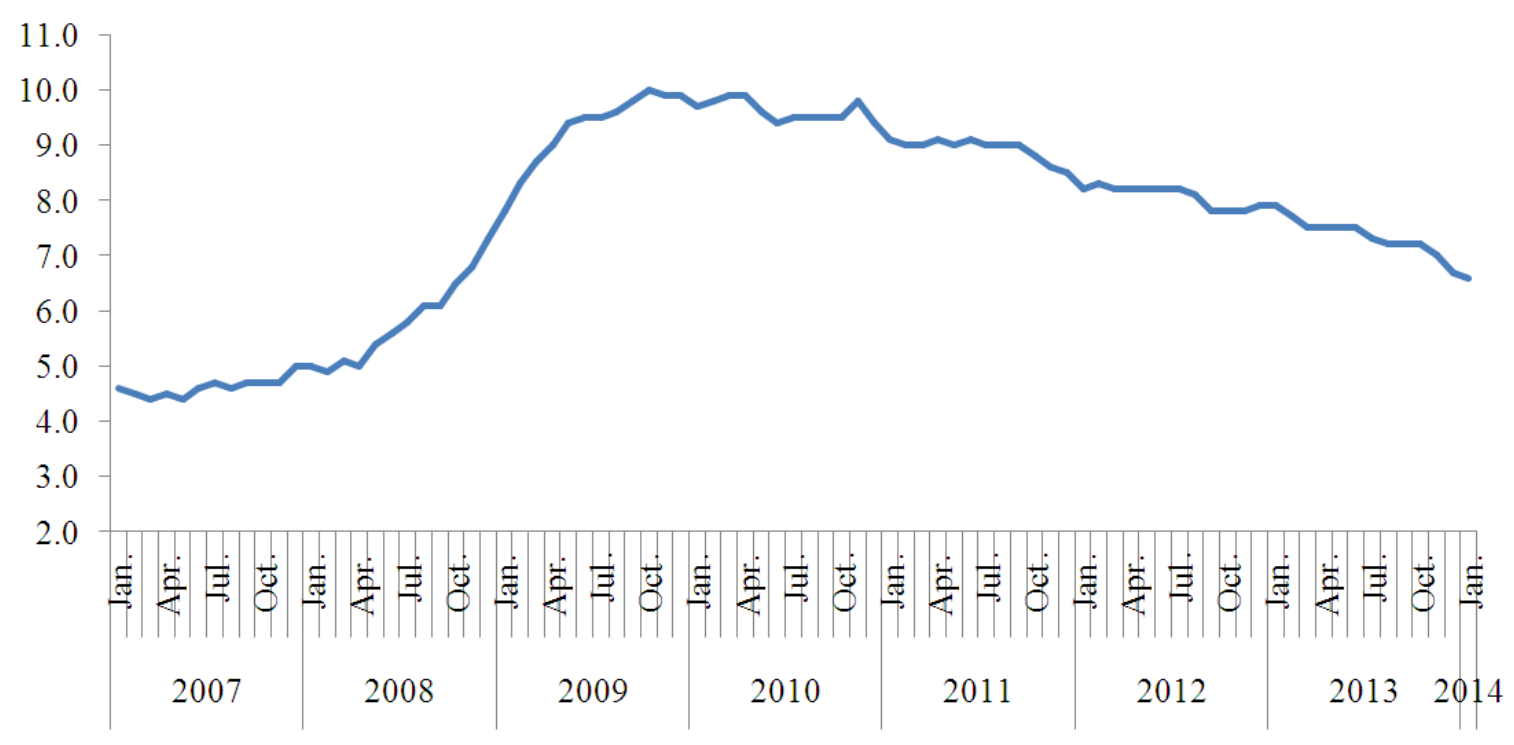

Fig. 5. Unemployment rates during the great recession

\section{THE CONTROVERSY ARISES}

There are some who argue that income inequality is not on the rise. They contend that the misguided perception of a greater gap stems from an assorted array of improper analytical processes, use of misleading data, ill-conceived methods of measurement and just simply measuring the wrong things. This failure to correctly recognize the issues surrounding the problem leads to false conclusion and fuzzy findings.

Furchtgott-Roth (2012) contends that it is per capita spending and not income that should be measured. She finds that inequality as measured by per capita spending is no greater today than in it was in the 1980s. Her conclusion is that published government spending data by income quintile show that the ratio of per person consumption between the top and bottom $20 \%$ has essentially not changed between 1985 and 2010. Notice she places the emphasis on spending and not income. Presumable, her assertion is that if spending among quintiles has not changed then neither has income.

She further supports her belief that general inequality has not changed by noting, as other other researchers point out, that many studies use measures of income before taxes are paid by the wealthy and before transfers, such as food stamps, Medicaid and housing allowances are handed over the poor. Including these transfers, these analysts point out, reduces inequality. This is pointed out in Fig. 3 above.
Furchtgott-Roth notes that many studies do not consider demographic changes in the composition of households over the past 30 years. Specifically, there are today more two-earner households at the top of the income scale and more one-person households at the bottom. This will further divide household earnings across the income stratum and give the impression that the income gap is expanding.

More than one-half of families in the highest-income quintile in 1990 had two earners with full-time, yearround jobs. In the lowest quintile, only $15 \%$ had two earners, with full-time, year-round work being the exception rather than the rule.

Finally, Furchtgott-Roth places blame for any perceived widening of the gap on the Tax Reform Act of 1986, which lowered top individual income-tax rates from 50 to $28 \%$. This encouraged more small businesses to file taxes under individual, rather than corporate, tax schedules. The rate has since been increased to $39.6 \%$ for incomes in excess of $\$ 400,000$ for those filing a single tax return $(\$ 406,751$ for 2014 taxes). The $28 \%$ now applies to those in the $\$ 87,850$ to $\$ 183,250$ bracket ( $\$ 89,351$ to $\$ 186,350$ for 2014 taxes).

Her entire premise is based on the claim that the superior measure of well-being is spending per person by income quintile. Spending, not income, is the proper measure of well-being among income groups because it is spending power that demonstrates how individuals are doing over time relative to others. An examination of 
these data from 1985, she states, shows that inequality has declined rather than increased.

However, one must question her position. Does spending really reflect income across quintiles or along the income continuum? Doesn't such an approach ignore the widely accepted dissimilarities in the propensity to consume among different income levels? It seems the disconnection between income and spending can generate misconceptions when applied to any strategy to measure economic well-being.

Findings by noted economist Robert Gordon (2009) suggest that the rise in American inequality has been exaggerated both in magnitude and timing. He maintains that a conceptually consistent measure of the growth in this gap over 1979 to 2007 is only one-tenth of that most often cited. He purports that by some measures inequality stopped growing after 2000 and by others that it has not risen measurable since 1993. Further, price indexes for the poor rise more slowly than for the rich, causing most empirical measures of inequality to overstate the growth of real income of the rich over the poor.

Gordon also offers the rather interesting comparison in the consumption pattern between the rich and the poor. He notes that the different market baskets each brings home favor the poor in terms of real costs. While the well-off purchase much more expensive commodities ranging from cars to food items, the poor subsist on less costly items. Their lower incomes therefore are offset by this more meager purchasing style. For example, he notes that as much as two-thirds of the post-1980 increase in the college wage premium disappears when allowance is made for the faster rise in the cost of living in cities where the college educated congregate. This actually, real difference in incomes is also dampened by the lower quality of housing in those cities.

The type of data used to measure inequality can dramatically affect the outcome. Reynolds (2007) points out that many estimates of rising inequality that are widely cited in the media are often based on federal income tax return data. Such analysis is not comparable over time due to changes in tax codes, tax rates and the ever-changing ways in which the government often defines taxable income. He points out that the reported income of high income taxpayers is very responsive to tax rates. When top tax rates on capital gains and wages fall, reported incomes rise. A larger fraction of the incomes of those in the upperechelon of the tax brackets show up on tax returns. Thus, studies that rely on IRS data are often distorted and disallow comparisons across time.
Chambers et al. (2014) offer support for the supposition that Americans enjoy a higher standard of living than many might perceive. Participants in their research consistently overestimated the size of the income gap and its growth over time. Much of this distortion resulted because participants exaggerated the incomes of top earners. They further inflated both the upper level of income that identified the top $1 \%$ of the wage-earners, as well as the percentage of Americans who fell in that exalted group. They contend that, in general, the degree of income inequality is not as extreme as many reports suggest.

Further comfort is extended by Schiller (2010) who offers the reassurance that the poor are not getting poorer. Although compared to the ultra-wealthy their share of the pie may have shrunk in the recent past, the pie itself has gotten much bigger. He cites growth in the gross domestic product over time as evidence that conditions may not be as dire as some perceive.

\section{SUMMARY}

While some authors and analysts bemoan the everwidening income gap, others insist it is not a cause for deep concern. Certainly, much of the data that have been collected indicate an incontrovertible increase in the income/wage gap throughout the U.S. Measures based on the Gini ratio clearly suggest that this separating of the classes has occurred in the recent past. This feature remains characteristic of the U.S. economy even after corrections for taxes placed on those in higher income brackets and transfers to those in lower brackets are taken into consideration.

Specific causes of measured income inequality can be identified. Economic downturns and global market factors exacerbate the dichotomy between the mega-rich and the less fortunate. The premium paid for college degrees has re-emerged causing a greater divide among those with differing educational levels and the requirement for a heightened level of technological acumen occasions greater partition among income cohorts.

The accelerated rate of globalization that has encouraged the outsourcing of many heretofore American jobs has also contributed to the problem of increased inequality. This fact, coupled with an unmistakable reduction in the level of unionization in the U.S. economy, has also made an impact in this regard.

However, not all the evidence is as depressing. Many researchers suggest that much of the inequality can be discounted based on the manner in which the data are collected. The use of IRS figures, for example, can distort the true nature of any income divide. Changes in tax laws prevent meaningful comparisons of income shares over time. 
Social and demographic changes in the U.S. over time also belie the true character of income differences. People in upper income levels more often have two income earners while those in lower income brackets more often find themselves relying on the support of only one bread winner in the household. This feature of the modern American family can cast concussion on the matter of the income gap.

Despite any discord regarding the depth and severity of income inequality, the issue will remain at the forefront of any socio-economic debate for at least the foreseeable future. It will no doubt occupy a position of central importance in the upcoming national elections.

\section{CONCLUSION}

It can be seen from the debate presented here that serious disagreement exists among researchers as to the threat presented by the prevailing level of income disparity. Lindert and Williamson (2011), Galbraith and other writers mentioned herein portend an eventual adverse outcome of this growing calamity.

On the proverbial other hand, Furchtgott-Roth and many of her contemporaries see no pending menace stemming from the dichotomy between the haves and the have-nots. Others such as Gordon even dispute the rise in any disparity.

Never-the-less, much of the available data offer what might be considered irrefutable evidence that a growing separation has indeed been in motion for several years. Such conditions, over time, can serve to benefit certain privileged segments of the socio-economic structure at the expense of the less fortunate.

Many might contend that conditions of glaring inequalities are unacceptable in a democratic system. Opportunity must be open to all if a free and open society is to function properly and fairly. Persistent discrepancies in financial means and affluence can effective impede economic growth and prosperity it can generate.

Income inequality is the result of a complex set of social, political, demographic and economic factors. The problem, to the extent that it exists, will not be solved by simple means. All forces at a nation's disposal must be brought to bear in order to mitigate the ill-effects of disparity. This will require the concerted and combined efforts of private and governmental interests as well as those that can be mustered by the will of the general public.

Future resources must also be devoted to further studies designed to discover effective means to combat income inequalities if our economy is to prosper and afford all citizens a path to a level of success commensurate to their skills, efforts and ambitions.
This recourse will involve changes in tax codes conducive to wide-spread parity, the expansion of opportunities to all interested individuals to augment their educational preparation as well as their professional and vocational aptitudes.

\section{REFRENCES}

Becker, G. and K. Murphy, 2007. The upside of income inequality. The American.

Blinder, A., 2007. Free trade's great, but offshoring rattles me. Washington Post.

BLS, 2014. Bureau of labor statistics.

Chambers, J.R., L.K. Swan and M. Heesacker, 2013. Better off than we know distorted perceptions of incomes and income inequality in America. Psychol. Sci. DOI: $10.1177 / 0956797613504965$

CBO, 2011. Trends in the distribution of household income between 1979 and 2007. Congressional Budget Office.

Furchtgott-Roth, D., 2012. The myth of increasing income inequality. Manhattan Institute for Policy Research, Inc.

Galbraith, J.K., 2012. Inequality and Instability: A Study of the World Economy Just Before the Great Crisis. 1st Edn., Oxford University Press, New York, ISBN-10: 019985565X, pp: 324.

Gini, C., 1912. Variabilitá e mutabilitá: Contributo allo studio delle distribuzioni e delle relazioni statistiche. Studi Economico-Giuridici Delta Regia Facoltà Giurisprudenza, 3: 3-159.

Gordon, R.J., 2009. Misperceptions about the magnitude and timing of changes in American income inequality. National Bureau of Economic Research.

Lindert, P.H. and J.G. Williamson, 2011. American incomes before and after the revolution. J. Econom History, 73: 725-765. DOI: $10.1017 / \mathrm{S} 0022050713000594$

Luhby, T., 2014. OECD Warns U.S. on Income Inequality. Cable News Network. A Time Warner Company.

Martel, J., 2014. Richest $85=$ wealth of ${ }_{3.5} \mathrm{~B}$ poorest. Oxfam.

Piketty, T. and E. Saez, 2003. Income inequality in the United States, 1913-1998. Q. J. Econom., 118: 1-39. DOI: $10.1162 / 00335530360535135$

Reynolds, A., 2007. Has U.S. Income Inequality Really Increased?. Cato Institute, Policy.

Schiller, B., 2010. The inequality myth. Wall Street J., 251: $15-18$.

WB, 2014. The world bank group. 